\title{
Leukoplakia Oris- an Enigma
}

\author{
Abhimanyu Mohanta* \\ Utkal University, India \\ Submission: July 29, 2017; Published: August 08, 2017 \\ *Corresponding author: Abhimanyu Mohanta, Biju Pattnaik College, Singda, Mayurbhanj, Odisha-757039, India, Tel: +91-9937575859; \\ Email: amohanta01@gmail.com
}

\section{Introduction}

The term 'leukoplakia' (Greek leuko-white, plak- plaquepatch) literally means 'white plaque' or 'white patch'. It has been attracted the clinicians and pathologists more than any other diseases after its first use by Schwimmer in 1877 [1]. Not only that, the definition of leukoplakia has also been changed from time to time [2,3]. The World Health Organizations (WHO) Working Group has redefined leukoplakia in 2007 as "a white plaques of questionable risk having excluded known diseases or disorders that carry no increased risk for cancer [4]." It is therefore a diagnosis of exclusion from other oral white lesions such as leukokeratosis, infective lesions (candidiasis, syphilitic oral lesion, oral hairy leukoplakia (caused by Epstein Barr virus), lichen planus, lupus erythematosus, dyskeratosis congenita, white sponge nevus, submucosal fibrosis and frank carcinomas $[5,6]$. Morsicatio mucosae oris (MMO) although appears to be a white papules and plaques that may resemble leukoplakia, but should not be confused any more. As reported by Woo and Lin, MMO is a form of chronic oral frictional keratosis which has no malignant potential at all, and so, it should be kept away from the category of leukoplakia [7].

On the basis of International Classification of Diseases and Related Health Problems, 10th Revision (ICD-10), there are six common cancer-prone sites in the oral cavity, such as lips (C00), tongue (dorsal $\mathrm{C} 01$, ventral- $\mathrm{C}_{2}$ ), alveolus and gingiva ( $\mathrm{C} 03$ ), floor of the mouth (C04), palate (C05) and buccal (cheek) mucosa (C06). Lip, tongue, floor of the mouth and buccal (cheek) mucosa are reported to be high-risk sites with regard to malignant transformation of leukoplakia in South-Asian countries, where various forms of tobacco and alcohol are consumed rampantly. However, appearance of leukoplakia at other sites of the oral cavity in other parts of the world may vary due to some other the etiologic factors.

Clinically two variants of leukoplakias, such as homogeneous leukoplakia and non-homogeneous leukoplakia are observed in different sites of the oral cavity including lips. Homogeneous leukoplakia is a lesion of uniform flat appearance that may exhibit superficial irregularities, but with consistent texture throughout. On the other hand, non-homogeneous leukoplakia appears to be predominantly white or white and red lesion (erythro-leukoplakia) with an irregular texture that may exhibits as a flat, nodular (speckled leukoplakia) or exophytic (or verrucous leukoplakia) lesion. The lesions are more common in the middle age group. However, advanced type of leukoplakia has also been observed among the younger generation in which school-going children are included who are used to chew various forms of processed tobacco (khaini, gutkha and paan masala).

In an extensive study on exfoliative oral cytopathology, Mohanta and Mohanty have reported that cytological pleomorphism was well observed in oral leukoplakia lesions. A number of diagnostic cytological atypias, such as Micronucleated cells (MNC), Plump keratinized squamous cells (PKSC), Keratinized spindle cells (KSC) and Keratinized tadpole cells (KTC) were observed in the exfoliated cytosmears of the leukoplakia cases. However, few more cytological atypias, like Keratinized strap (Anitschkow) cells (KSC-A), Keratinized fibre cells (KFC) and keratinized round cells (KRC) were also rarely found among erythro-leukoplakia cases, but frequently observed in benign / carcinoma in situ (CiS) and malignant neoplasm cases. Of these cytological atypias, except PKSC, presence of KSC, KTC, KSC-A, KFC and KRC at leukoplakia stage clearly indicates the potentiality of malignancy [8] and MNC is considered to be a potential biomarker of oral carcinogenesis [9].

Clinicopathologically, both speckled leukoplakia and verrucous leukoplakia frequently show severe dysplasia and greater tendency towards epidermoid carcinoma than the simple homogeneous leukoplakia in the oral cavity. On the basis of clinicopathological review, vander Waal et al. [10] have also reported that leukoplakia is the most common premalignant or potentially malignant lesion of the oral mucosa shows various degrees of epithelial dysplasia. According to them, although epithelial dysplasia is an important predictive factor of malignant transformation, it should be realized that not all dysplastic lesions will become malignant. On the other hand, non-dysplastic lesions may become malignant as well [10]. Interestingly, more than $90 \%$ oral leukoplakias mimic to be a mere plaque or white 
lesions, but have a tremendous potentiality for malignant transformation in due course of time irrespective of oral sites and sexes. A number of factors such as age, type of lesion, site and size, dysplasia, and DNA content have been associated with increased risk of malignant transformation, but no single reliable biomarker has been shown to be predictive. Etiological factors such as addiction to smoked and non-smoked tobacco, chewing of khaini, gutkha and betel quids as well as drinking of alcohol are reported to trigger the process of malignant transformation.

Due to diabolical diagnostic dilemma, 'Oral leukoplakia-to treat or not to treat' is a question of reality raised by Holmstrup \& Dabelsteen [11] has its own relevance but at a cross-road! Considering the pathologic gravity of oral leukoplakia, various non-surgical and surgical treatments for oral leukoplakia have been reported. Apart from the conventional surgical excision, various treatment modalities such as $\mathrm{CO}_{2}$-laser surgery, Diode laser surgery, Cryosurgery, and Photodynamic therapy have been implemented. In a comparative evaluation for surgical management of oral leukoplakia, Natekar et al. [12] have found that laser therapy $\left(\mathrm{CO}_{2}\right.$ laser and Diode laser $)$ seems to offer better clinically significant results than cryosurgery [12]. Ishii et al. have reported that after some treatments, oral leukoplakias show recurrence and/or malignant transformation, even following complete resection. Furthermore, patients with oral leukoplakia may develop new lesions in other sites of the oral cavity [13]. Therefore, currently there is no universal consensus on the most appropriate and effective treatment modality for prevention of malignant transformation and recurrence of oral leukoplakia.

Leukoplakia oris is really an enigmatic lesion in the oral cavity. Neither biological nor clinico-pathological behaviour of such oral premalignant lesion is completely understood. Ambiguity over etiopathology of leukoplakia oris has been still persisting. Harbouring a number of diagnostic cytological atypias which are reported to be sign and index of malignant potentiality as well as unpredictable epithelial dysplasia in leukoplakia turn the lesions into more mysterious one. Considering these facts, a more comprehensive definition is proposed herewith to define the term 'leukoplakia'. Unambiguously, leukoplakia may be defined as 'a predominantly non-scrapable, either homogeneous or heterogeneous, irreversible white epidermoid premalignant oral lesion having the potentiality of malignant transformation irrespective of oral site and sex which cannot be characterized/ categorized clinicopathologically as any other definable disease and is usually associated with the addiction to tobacco, betel quid, and alcohol'. Also, a holistic approach is to be taken into consideration for the effective treatment of the oral leukoplakia cases.

\section{References}

1. Schwimmer E (1877) Die idiopathischen Schleim haut plaques der Mundhöhle Arch Dermat Syph 9: 570-611.

2. Axell T, Holmstrup P, Kramer IR, Pindborg JJ, Shear M (1984) International seminar on oral leukoplakia and associated lesions related to tobacco habits. Community Dent Oral Epidemiol 12: 145-154.

3. Axell T, Pindborg JJ, Smith CJ, van der Waal I (1996) Oral white lesions with special reference to precancerous and tobacco-related lesions: Conclusions of an international symposium held in Uppasala, Sweden, May 18-21, 1994. International Collaborative Group on Oral White Lesions. J Oral Pathol Med 25(2): 49-54.

4. Warnakulasuriya S, Johnson NW, van der Waal I (2007) Nomenclature and classification of potentially malignant disorders of the oral mucosa. J Oral Pathol Med 36(10): 575-578.

5. Mishra M, Mohanty J, Sengupta S, Tripathy S (2005) Epidemiological and clinicopathological study of oral leukoplakia. Indian J Dermatol Venereol Leprol 71(3): 161-165.

6. Odukoya O, Roberts T, Aroll G (1990) A cytologic study of the effect of Kolanut on the keratinization of the palatal mucosal of Nigerian smokers. Afr Dent J 4(1-5):1-5.

7. Woo SB, Lin D (2009) Morsicatio Mucosae Oris-A Chronic Oral Frictional Keratosis, Not a Leukoplakia. J Oral Maxillofac Surg 67(1): 140146.

8. Mohanta A, Mohanty PK (2017) Nuclear pleomorphism-based cyto pathological grading in human oral neoplasm. Russian Open Medical Journal 6(2): 1-10.

9. Mohanta A, Mohanty PK (2017) Oral Micro nucleated Cells-A Cyto diagnostic Approach. Adv Cytol Pathol 2(2): 00013.

10. van der Waal I, Schepman KP, van der Meij EH, Smeele LE (1997) Oral leukoplakia: a clinicopathological review. Oral Oncol 33(5): 291-301.

11. Holmstrup P, Dabelsteen E (2016) Oral leukoplakia-to treat or not to treat. Oral Dis 22(6): 494-497.

12. Natekar M, Raghuveer HP, Rayapati DK, Shobha ES, Prashanth NT, et al. (2017) A comparative evaluation: Oral leukoplakia surgical management using diode laser, CO2 laser, and cryosurgery. J Clin Exp Dent 9(6): e779-e784.

13. Ishii J, Fujita K, Komori T (2003) Laser surgery as a treatment for oral leukoplakia. Oral Oncol 39(8): 759-769. 
(C) This work is licensed under Creative Commons Attribution 4.0 Licens
Your next submission with Juniper Publishers will reach you the below assets

- Quality Editorial service

- Swift Peer Review

- Reprints availability

- E-prints Service

- Manuscript Podcast for convenient understanding

- Global attainment for your research

- Manuscript accessibility in different formats ( Pdf, E-pub, Full Text, Audio)

- Unceasing customer service

Track the below URL for one-step submission https://juniperpublishers.com/online-submission.php 